\title{
Effects of Lactose, Ethanol and Cycloheximide on the Translocation Pattern of Radioactive Compounds and on Sclerotium Formation in Sclerotium rolfsii
}

\author{
By Y. OKON, I. CHET AND Y. HENIS \\ Department of Plant Pathology and Microbiology, \\ The Hebrew University of Jerusalem, Faculty of Agriculture, Rehovot, Israel \\ (Received 23 May 1972; revised 17 August 1972) \\ SUMMARY \\ Protein synthesis and translocation of $\mathrm{L}-\left[{ }^{14} \mathrm{C}\right]$ leucine, $\mathrm{D}-\left[{ }^{14} \mathrm{C}\right] \mathrm{glucose}$ and \\ inorganic ${ }^{32} \mathrm{P}$ were enhanced in cultures of Sclerotium rolfsii Sacc. grown on medium \\ supplemented with $0.5 \%$ lactose. Ethanol $(2 \%, \mathrm{v} / \mathrm{v})$ inhibited translocation but \\ not protein synthesis. Neither lactose nor ethanol affected the uptake of radioactive \\ substances by the fungal mycelium. Cycloheximide applied to the colony margins \\ prevented sclerotium formation and protein synthesis without inhibiting transloca- \\ tion. It was concluded that translocation and protein synthesis in $S$. rolfsii are \\ independent processes and are both essential for sclerotium formation.
}

\section{INTRODUCTION}

The growth and development of fungi are intimately linked with the translocation of materials within hyphae (Zalokar, I959; Watkinson, 1971 $a$ ). Studies with labelled materials indicate that, with certain sclerotium-forming fungi, translocation often results in the accumulation of substances in the developing sclerotia. For example, Littlefield, Wilcoxson \& Sudia (1965) showed that translocated ${ }^{32} \mathrm{P}$ accumulated in sclerotia of Rhizoctonia solani. Translocation was resumed when sclerotial primordia formed, but not in cultures that formed no sclerotia nor in those from which sclerotia were removed before ${ }^{32} \mathrm{P}$ application. The age, size and location of sclerotia had no consistent effect on the degree of accumulation (Littlefield, 1967). Wilcoxson \& Subbarayudu (1968) found that ${ }^{32} \mathrm{P}$ was translocated and accumulated in sclerotia of Sclerotium rolfsii and to a significantly greater extent when the direction of translocation was from the old to the young portion of the cultures than when in the reverse direction. Accumulation of ${ }^{14} \mathrm{C}$-labelled iodoacetic acid in sclerotia of $S$. rolfsii was reported by Chet, Henis \& Mitchell (1966).

The purpose of this work was to study the relationship between translocation and sclerotium formation in Sclerotium rolfsii under conditions which led to synchronous formation of sclerotia (Okon, Chet \& Henis, 1972).

\section{METHODS}

Organism and growth conditions. Sclerotium rolfsii Sacc. (isolated from sugar beet) was grown on a synthetic agar medium (SM), containing $(\mathrm{g} / \mathrm{l}): \mathrm{MgSO}_{4} \cdot 7 \mathrm{H}_{2} \mathrm{O}, 0.2 ; \mathrm{K}_{2} \mathrm{HPO}_{4}$, $0.9 ; \mathrm{KCl}, 0.2 ; \mathrm{NH}_{4} \mathrm{NO}_{3}, \mathrm{I} \cdot 0$; glucose, $15 ; \mathrm{Fe}^{2+}, 0.002 ; \mathrm{Mn}^{2+}, 0.002 ; \mathrm{Zn}^{2+}, 0.002 ;$ thiamine hydrochloride, $0 \cdot 000 \mathrm{r}$; agar (Difco), 20; in d distillewater; $\mathrm{pH} 6 \cdot 8$.

Agar discs ( $\mathrm{cm}$ diam.) covered with mycelium were cut from 5-day-old cultures and 


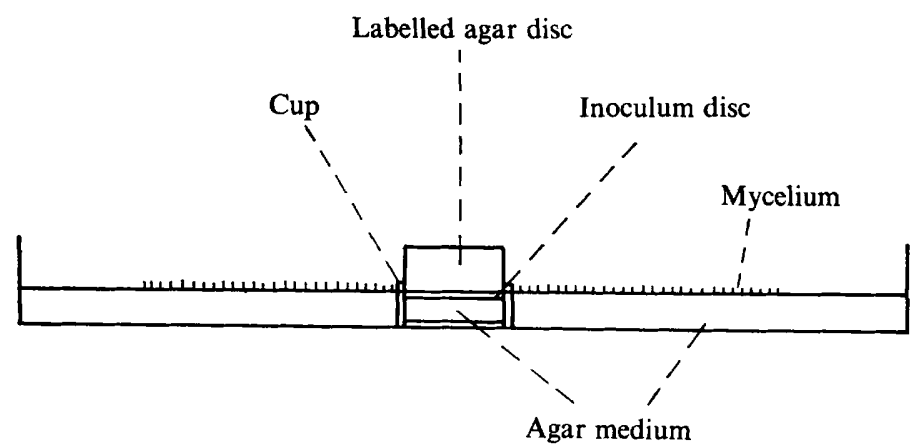

Fig. I. Diagram of Petri dish culture used for studying translocation in mycelium of Sclerotium rolfsii.

used as inocula. Plates were incubated at $30^{\circ} \mathrm{C}$. Each treatment within an experiment was replicated six times and each experiment was repeated four times.

Labelled compounds. L- $\left[{ }^{14} \mathrm{C}\right]$ Leucine (specific activity, $10 \mathrm{mCi} / \mathrm{mM}$ ) and $\mathrm{D}-\left[{ }^{14} \mathrm{C}\right]$ glucose (specific activity, $2.9 \mathrm{mCi} / \mathrm{mm}$ ) were obtained from the Radiochemical Centre, Amersham, Buckinghamshire. Inorganic ${ }^{32} \mathrm{P}$ was obtained from the Nuclear Research Centre, Dimona, Israel.

Translocation and distribution of labelled compounds. A sterile plastic cup ( $\mathrm{I} \cdot 2 \mathrm{~cm}$ diam. with walls $4 \mathrm{~mm}$ high) was placed in the centre of each Petri dish containing $10 \mathrm{ml}$ SM. It was filled with $0.5 \mathrm{ml}$ of the same medium and inoculated with a $\mathrm{I} \mathrm{cm}$ disc. The fungus was grown for 4 days. Labelling was done by adding a distilled water-agar (2\%) disc (I cm diam.) containing $0 \cdot 2 \mu \mathrm{Ci}$ of radioactive substance (Fig. I).

Agar discs (0.8 cm diam.) covered with mycelium (but not sclerotial initials) were taken from the margins of the growing cultures, at intervals, and tested for radioactivity. 'Reversed' translocation was measured by labelling the colony margins with a disc of radioactive agar, and testing agar discs covered with mycelium sampled from the colony centre.

Radioactivity of the discs was measured by a Packard Liquid Scintillation Spectrometer (model 3003). Radial strips $(0.5 \mathrm{~cm}$ wide) of agar covered with mycelium were cut from the colony 24 and $48 \mathrm{~h}$ after labelling and dried by infrared light on Whatman no. I filter paper. The distribution of radioactivity along the strip was measured by a Packard Radiochromatogram Scanner (model 7200).

To evaluate the extent of passive diffusion of radioactive compounds into the agar, the fungus was grown on a cellophane membrane placed on the agar and labelled as described above. Agar discs were taken from beneath the cellophane and their radioactivity measured. The possibility of passive transport of radioactive compounds was examined by following translocation in cultures which had been killed by chloropicrin.

Uptake and incorporation of labelled compounds. The fungus was grown for 4 days on a cellophane membrane placed on the surface of a synthetic agar medium containing lactose $(0.5 \%)$, ethanol $(2 \%, \mathrm{v} / \mathrm{v})$ or both. The cellophane with the fungus was transferred to plates containing $20 \mathrm{ml}$ liquid medium, supplemented with leucine or glucose (each at $0 \cdot \mathrm{I} \mu \mathrm{Ci} / \mathrm{ml}$ ), and glass beads as a mechanical support. After $2 \mathrm{~h}$ the mycelium was collected from the cellophane, washed with $0 \cdot \mathrm{I} \mathrm{M}$-phosphate buffer $(\mathrm{pH} 7 \cdot 0)$ until no radioactivity could be detected in the buffer, dried at $80^{\circ} \mathrm{C}$ for $24 \mathrm{~h}$, weighed and tested for radioactivity.

Incorporation of $\mathrm{L}-\left[{ }^{14} \mathrm{C}\right]$ leucine into trichloroacetic acid-insoluble material was determined after homogenization of the outer $5 \mathrm{~mm}$ of the colony margins by Omnimixer (Sorvall) for 
$2 \mathrm{~min}$ at $8000 \mathrm{rev} . / \mathrm{min}$. The homogenate was centrifuged at $10000 \mathrm{~g}$ for $10 \mathrm{~min}$. Trichloroacetic acid (final concentration $5 \%, v / v$ ) was added to the supernatant and the resulting precipitate washed three times with trichloroacetic acid $(5 \%)$ by centrifugation. Protein content of the pellet was determined with the Folin phenol reagent prepared as described by Lowry, Rosebrough, Farr \& Randall (195I).

Extraction and analysis of free amino acids. A culture of Sclerotium rolfsii was grown on a cellophane membrane placed on SM supplemented with lactose, ethanol or both. After 3 days of incubation, hyphal tips were collected at a distance of $5 \mathrm{~mm}$ from the colony margin, homogenized for 2 min with $3 \mathrm{ml}$ of $5 \times 10^{-3} \mathrm{~N}-\mathrm{HCl}(\mathrm{pH} 2.5)$ and centrifuged at I $5000 \mathrm{~g}$ for $10 \mathrm{~min}$. The supernatant was mixed with trichloroacetic acid (final concentration $5 \%, \mathrm{v} / \mathrm{v}$ ) and centrifuged again at $5000 \mathrm{~g}$ for $5 \mathrm{~min}$. It was then washed five times with diethyl ether and lyophilized. The residue was dissolved in $2 \mathrm{ml} 0.2 \mathrm{~N}$-citrate buffer $(\mathrm{pH}$ 2.2) and analysed with a Bio Cal-200 amino acid analyser.

The effect of cycloheximide on sclerotium formation. A circle of Whatman no. I filter paper, $0.5 \mathrm{~cm}$ wide and $6.0 \mathrm{~cm}$ in internal diam., was soaked with $0.2 \mathrm{ml}$ cycloheximide solution $(5 \mathrm{mg} / \mathrm{ml})$, air-dried and placed around a 3 -day-old colony of Sclerotium rolfsii. The central region of the agar was isolated by a plastic cup $(3 \mathrm{~cm} \mathrm{diam}$.).

\section{RESULTS}

Effect of lactose and ethanol on translocation. Sclerotium rolfsii was grown on SM supplemented with lactose, ethanol or both. Labelled compounds were added to the central cup when the colony diameter reached $50 \mathrm{~mm}$ on the medium containing lactose or $80 \mathrm{~mm}$ on a medium without lactose.

Translocation patterns of radioactivity originating from leucine, glucose and phosphate are shown in Fig. 2.

Passive absorption by the mycelium and diffusion of radioactivity in controls of dead mycelium and agar discs, taken from beneath the cellophane membrane, did not exceed $5 \%$, as compared with living mycelium.

No 'reversed' translocation could be detected. In general, translocation of radioactivity within the fungus was greater when grown on $\mathrm{SM}+$ lactose than on $\mathrm{SM}+$ lactose + ethanol (Fig. 2). No significant differences in translocation were observed when ethanol alone was added to SM (Fig. 2). When the fungus was grown on SM without ethanol, most of the radioactivity was translocated into sclerotial initials which were not formed in ethanolcontaining medium (Table I).

Application of cycloheximide to the margins of a colony grown on lactose resulted in inhibition of sclerotium formation. However, no effect on translocation was observed (Fig. 2).

Distribution in the fungal mycelium of radioactivity originating from various labelled compounds $48 \mathrm{~h}$ after labelling is shown in Fig. 3. Similar patterns were observed after $24 \mathrm{~h}$.

No significant variation was observed among replicates.

Uptake of leucine and glucose. Cellophane-grown cultures were incubated on a liquid medium containing $\mathrm{L}-\left[{ }^{14} \mathrm{C}\right]$ leucine or $\mathrm{D}-\left[{ }^{14} \mathrm{C}\right]$ glucose. No significant differences in uptake of radioactivity ( $1520 \pm 8 \%$ and $800 \pm 6 \%$ c.p.m./mg dry wt, respectively) could be detected between cultures grown on SM, SM+lactose, SM+ethanol or SM+lactose + ethanol.

Incorporation of $\mathrm{L}-\left[{ }^{14} \mathrm{C}\right]$ leucine into the trichloroacetic acid-insoluble mycelial fraction increased in fungus grown on SM+lactose compared to the synthetic medium, and was significantly inhibited by cycloheximide (Table 2 ). 


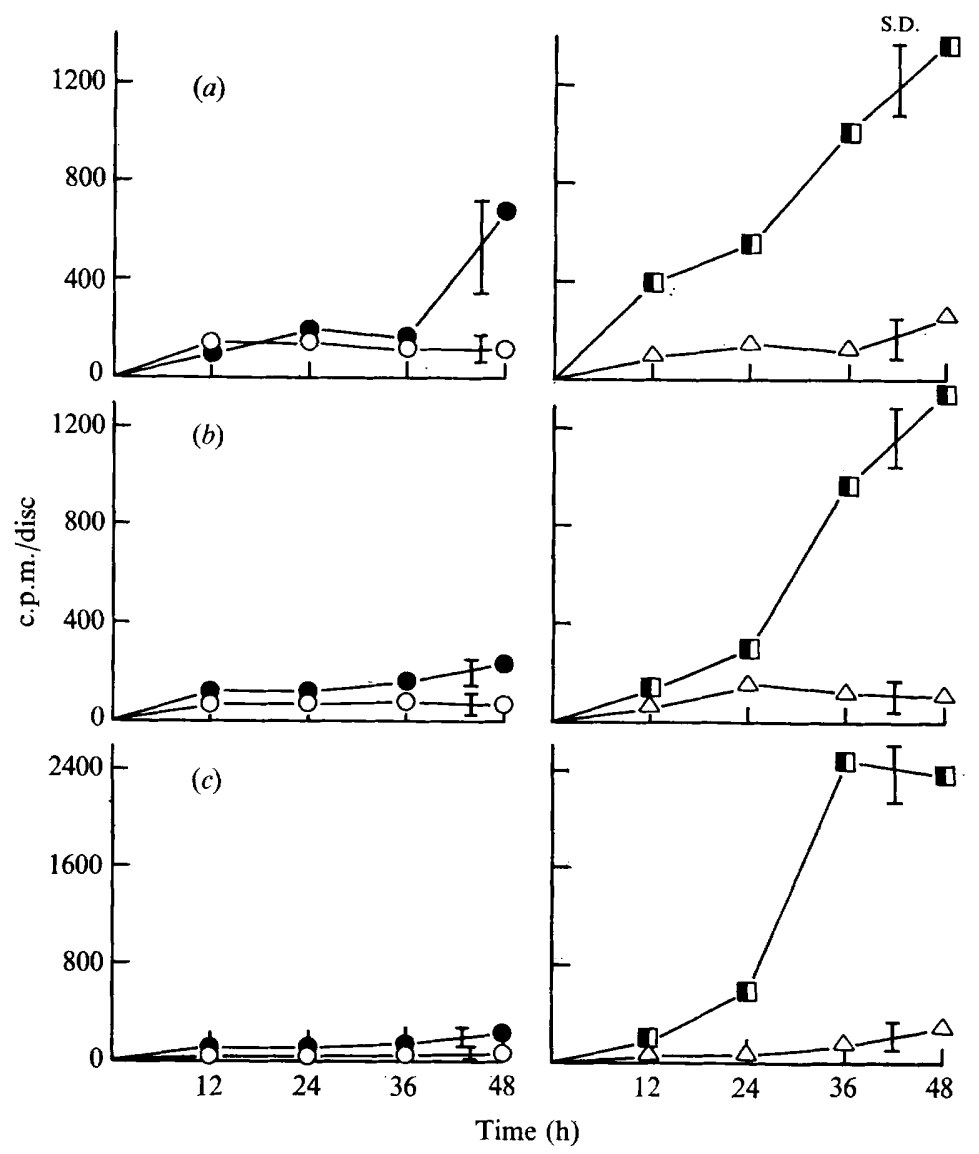

Fig. 2. The effect of lactose, ethanol and cycloheximide on the translocation of $\mathrm{L}-\left[{ }^{14} \mathrm{C}\right]$ leucine $(a)$; $\left[{ }^{14} \mathrm{Clglucose}(b)\right.$; and inorganic ${ }^{32} \mathrm{P}(c)$ in Sclerotium rolfsii. Synthetic medium (SM), $\mathrm{SM}+$ ethanol $(2 \%, \mathrm{v} / \mathrm{v}), \mathrm{O}-\mathrm{O} ; \mathrm{SM}+$ lactose $(0.5 \%, \mathrm{w} / \mathrm{v}), \mathbf{\square}-\mathbf{\square} ; \mathrm{SM}+$ lactose + cycloheximide, $\square-\square$; SM +lactose + ethanol, $\triangle-\triangle$.

Table I. Effect of ethanol on accumulation of radioactive compounds in mycelium and sclerotial initials of Sclerotium rolfsii

\section{Radioactive compounds} (c.p.m./mg dry wt)

\begin{tabular}{llccc}
\multirow{2}{*}{ Growth medium } & Structure & $\overbrace{\left[{ }^{14} \mathrm{C}\right] \text { Leucine }}$ & {$\left[{ }^{14} \mathrm{C}\right]$ Glucose } & {$\left[{ }^{32} \mathrm{P}\right]$ Phosphate } \\
SM & Initials & 690 & 190 & Iro \\
& Mycelium & I 14 & 90 & 33 \\
SM+ethanol $2 \%(\mathrm{v} / \mathrm{v})$ & Mycelium & 48 & 52 & 33
\end{tabular}



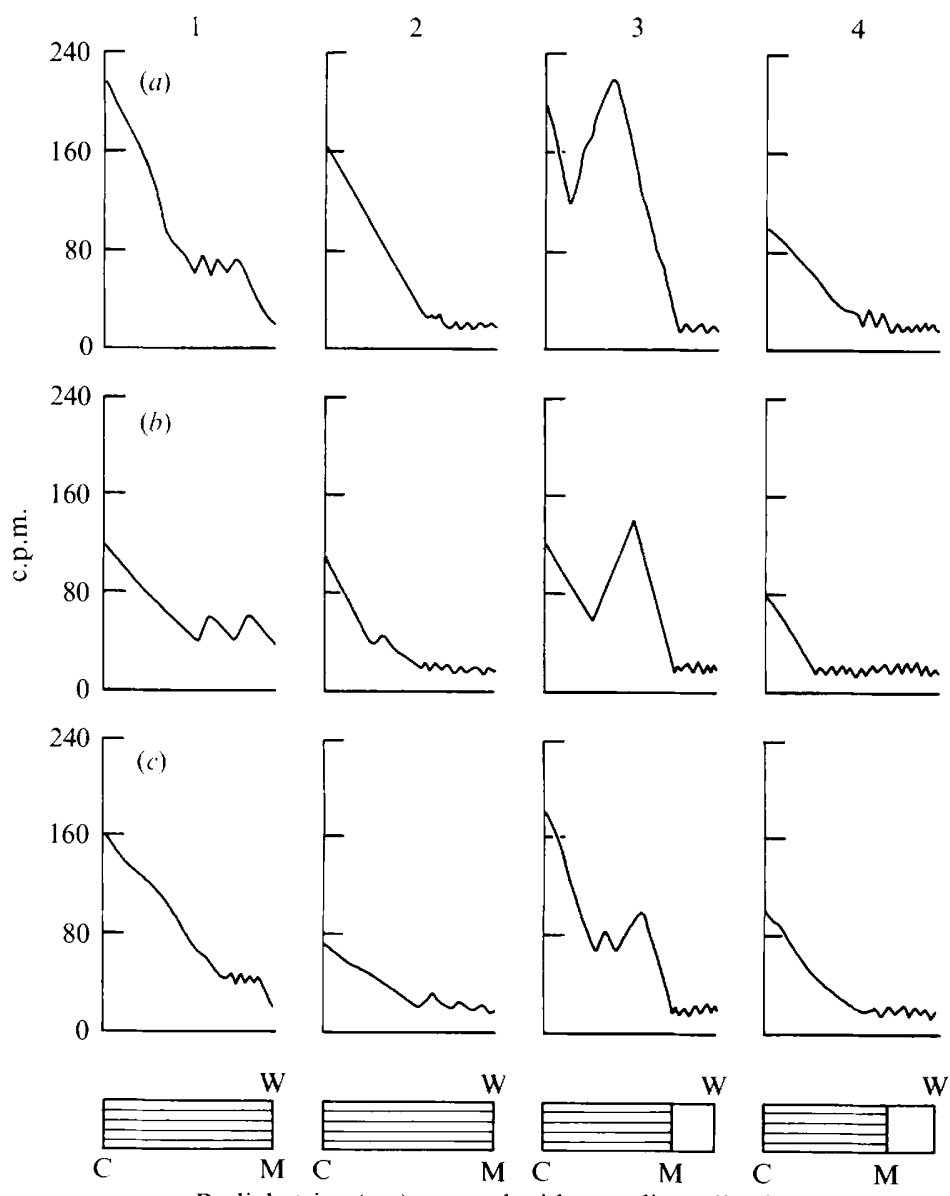

Radial strips (cm) covered with mycelium (lined area)

Fig. 3. The distribution of $\mathbf{L}-\left[{ }^{14} \mathrm{C}\right]$ leucine $(a),\left[{ }^{14} \mathrm{C}\right]$ glucose $(b)$, and inorganic ${ }^{32} \mathrm{P}(c)$ along dried radial strips of Sclerotium rolfsii mycelium as detected by a Radiochromatogram Scanner. Synthetic medium (SM), I; SM + ethanol $(2 \%, \mathrm{v} / \mathrm{v}), 2 ; \mathrm{SM}+$ lactose $(0.5 \%, \mathrm{w} / \mathrm{v}), 3 ; \mathrm{SM}+$ lactose + ethanol, 4. Radioactivity in radial strips was measured from colony centre $(C)$ to colony margins $(M)$. Petri dish walls, W.

Table 2. Incorporation of $\mathrm{L}-\left[{ }^{14} \mathrm{C}\right]$ leucine into the trichloroacetic acid-insoluble fraction in Sclerotium rolfsii

$$
\text { Growth medium (c.p.m./mg protein) }
$$

$\begin{array}{lr}\text { SM } & 5285 \mathrm{~b}^{*} \\ \text { SM + lactose } 0.5 \%(\mathrm{w} / \mathrm{v}) & \text { I } 7540 \mathrm{a} \\ \text { SM + lactose + cycloheximide } & \text { I300 c } \\ \text { SM + ethanol 2\%(v/v) } & 4990 \mathrm{~b} \\ \text { SM + lactose + ethanol } & \text { I } 4000 \mathrm{a}\end{array}$

* Numbers accompanied by the same letter did not differ significantly at the $5 \%$ probability level, using Duncan's multiple-range test. 


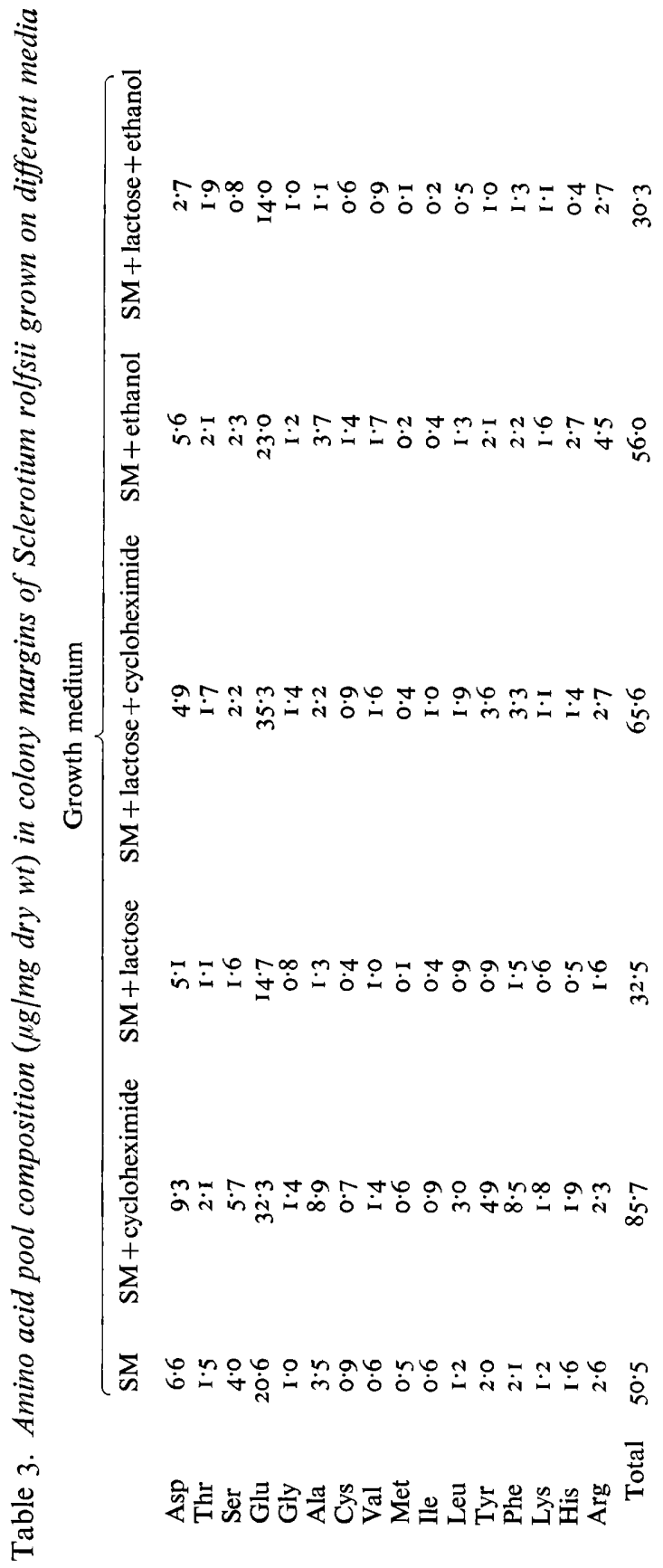


Free amino acid conten of hyphal tips. The free amino acid pool in the colony margins of the fungus grown on lactose medium was significantly lower than that of a colony grown on a non-supplemented medium. On the other hand, cycloheximide appreciably increased the free amino acid pool in both treatments (Table 3 ).

\section{DISCUSSION}

Wilcoxson \& Subbarayudu (I968), working on fungal translocation, noted that their data did not completely separate absorption by mycelium from translocation. Watkinson (I97I $b$ ), who used the split-plate method of Lucas (1960), killed the mycelium and showed that there was no diffusion between the two halves of the plate.

The techniques described in this paper provide an efficient method for studying both distribution (by means of the Radiochromatogram Scanner) and translocation of radioactive compounds in fungi and enable a distinction to be made between absorption by mycelium, diffusion in agar and translocation.

Translocation of various radioactive compounds was enhanced in cultures grown on lactose-supplemented (as compared with a non-supplemented) medium, could be detected before the onset of any morphological changes, and accompanied sclerotium formation. This enhanced translocation, with the concomitant partial inhibition of mycelial linear growth, could be the cause of the formation of a circle of sclerotia at the colony margins.

In contrast to lactose, ethanol drastically decreased translocation of the compounds tested with only a slight inhibition of linear growth (Okon et al. 1972), but with a total inhibition of sclerotium production. Neither lactose nor ethanol affected uptake of radioactive compounds by the fungal mycelium. These results support the suggestion that internal translocation is related to morphogenesis (Zalokar, 1959; Watkinson, I97I $a$ ).

In addition to its effect on translocation, lactose induced a preferential incorporation of $\left[{ }^{14} \mathrm{C}\right]$ leucine into trichloroacetic acid-insoluble material at the colony margins, with a concomitant decrease in the free amino acid pool, indicating an increase in protein synthesis before the appearance of sclerotial initials at this site.

Though it affected translocation, ethanol did not affect the composition and level of the amino acid pool nor leucine incorporation into the trichloroacetic acid-insoluble fraction.

Application of cycloheximide to colony margins prevented sclerotium formation but not the translocation of radioactive compounds, either in the presence or absence of lactose. It can therefore be concluded that lactose stimulates amino acid translocation and incorporation independently, both processes being essential for sclerotium formation in Sclerotium rolfsii.

\section{REFERENCES}

Chet, I., Henis, Y. \& Mitchell, R. (I966). The morphogenetic effect of sulphur-containing amino acids, glutathione and iodo-acetic acid on Sclerotium rolfsii Sacc. Journal of General Microbiology 45, 54I-546.

LitTlefield, L. J. (1967). Phosphorus-32 accumulation in Rhizoctonia solani sclerotia. Phytopathology 57, 1053-1055.

LitTlefield, L. J., Wilcoxson, R. D. \& SudiA, T. W. (I965). Translocation of phosphorus-32 in Rhizoctonia solani. Phytopathology 55, 536-542.

Lowry, O. H., Rosebrough, N. J., Farr, A. L. \& Randall, R. J. (195I). Protein measurement with the Folin phenol reagent. Journal of Biological Chemistry 193, 265-275.

LUCAs, R. L. (1960). Transport of phosphorus by fungal mycelium. Nature, London 188, 763-764.

OKon, Y., Chet, I. \& Henis, Y. (1972). Lactose-induced synchronous sclerotial formation in Sclerotium rolfsii and its inhibition by ethanol. Journal of General Microbiology 71, 465-470. 
WatKINSON, S. C. (1971 $a$ ). The mechanism of mycelial strand induction in Serpula lacrimans: a possible effect on nutrient distribution. New Phytologist 70, 1079-1088.

WatKinson, S. C. (197I $b$ ). Phosphorus translocation in the stranded mycelium of Serpula lacrimans. Transactions of the British Mycological Society 57, 535-539.

Wilcoxson, R. D. \& Subbarayudu, S. (I968). Translocation and accumulation of phosphorus-32 in sclerotia of Sclerotium rolfsii. Canadian Journal of Botany 46, 85-88.

Zalokar, M. (1959). Growth and differentiation of Neurospora hyphae. American Journal of Botany 46, 602-610. 